\title{
How to influence the Job rotation of the employee on intelectual risk in the service industry
}

\author{
Muhammad Ibrar \\ Department of Business Adminstration (Human Resource Management) \\ E-mail address:dr.mibrar1002@gmail.com
}

Keywords: Intellectual capital risks, Intellectual capital management, Knowledge attrition, Job rotation, Intellectual capital, Multinational companies

\section{ABSTRACT}

Purpose: This study aims to stress on the phenomenon of intellectual capit (IC) co More precisely, the perception of such risks in the context of the job rotati roce os oft $n$, pplied in multinational corporations (MNCs) is to be investigated.

Design/methodology: Seven semi-structured interviews are cond ed in an es ary knowledgeintensive MNC operating in the construction industry. Six inte iem mong top nanagers and five interviews among participants in the job rotation process carrio to gain insights from different perspectives.

Findings: The study emphasize the influence of time ressure on the perception of the variety of IC-related risks in general and of those related to the $j$ rotation pr cess. As a result, the risks are not tackled even though the managers are aware of some them.

Research limitations/implication: The data $v$ collecteu one organization, making inferences about the findings not possible. Future studies s Dur cider multiple organizations.

Practical implications: A list of potential IC is s trig sered during the job rotation process is presented and suggestions to tackle th re disc sed. Furthermore, the findings can contribute to the further development of an over 11 ove iew of 1 Yisks.

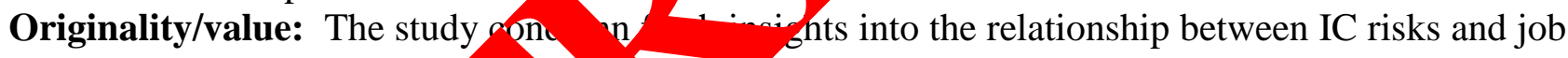
rotation as perceived by diffe entorga ation members.

\section{INTRODUCTION}

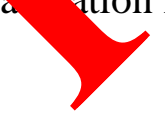

This study focus which th Atellectual capital (IC) is a significant resource and vital production fact of a o npanies heed to integrate the management of intellectual capital (IC) into the core of the ategic forts. However, many companies lack understanding about the requiremer for $\mathrm{m}$ oing $\mathrm{IC}$ and the complexity involved, not surprisingly, the majority of corpore e in tives fo sing on the management of IC/knowledge have only moderate success (His 005 IC management entails difficulties because it does not only involve decisions from managers allocation of resources as it is the case in many other management issues. IC is created or e rited by human beings and is therefore influenced by individuals and their mindsets, organizational values and beliefs as well as the full commitment of all organization members. Companies that fail to properly manage their IC to secure its value-creation potential undergo significant risks. For example loss of expertise or reinvention of knows how. Therefore, the need to carefully manage the risky side of IC is high too. Manager's and entrepreneurs cannot afford to neglect IC risks even though they might be more familiar with financial capital and the risks related to this asset category.

According to Kupiet al.(2008), the attention to IC risk management in companies is poor. One reasonfor this can be a lack of awareness related to the implications of IC risks. As a result,such risks are seldom identified, monitored and reported.It can be proceeded from the assumption that particularly multinational corporations(MNCs) need to engage in IC risk management. A 
multinational corporation "consists ofa group of geographically dispersed and goal-disparate organizations that include itsheadquarters and the different national subsidiaries" (Ghoshal and Bartlett, 1990, p. 603).Such MNCs face more challenges to stay competitive and keep up with dynamic changes in international markets given their size and organizational structure compared to smaller internationally operating companies. Increasing administration effort leads to numerous hierarchical levels with many specialists. Particularly, the costs and effort for communication, control and coordination are high (Gooderham and Nordhaug, 2003). To remain competitive, MNCs need to create and leverage distinctive organizational capabilities. To tackle this issue MNCs can refer to different approaches. One of the common measure applied by MNCs is job rotation. Even though the job rotation process can be viewed as advantageous for IC management, it also entails risks. The change from the predecessor to the successor is a critical stage. If the mecessor documented no knowledge, the "newcomer" needs to fight his or her way to neces ary kno dge to fulfil tasks satisfactorily. Such an undefined handling of knowledge can be ris knowledg tets lost during the job rotation process. This brief discussion illustrates the jopor of $\mathrm{h}$ ing suitable measures in place to tackle IC risks as well as the close link boween IC a job rotation. Although IC has been studied extensively, this is not the car vith ts rela do IC. Against this background, the study's aim is to shed light on the man ern reeptio of IC risks. Specifically, it is targeted on establishing an understanding about I/ risks cau by $/$ ie job rotation process. Consequently, the study addresses three research

Research Questions:

* RQ1.Is IC risk already in the minds of managers

* RQ2.Are managers aware of IC related risks dr ing job rotation?

* RQ3. What are the IC related risks experienced y rotating e nployees?

Following a review of previous literature a methodology employed in the study, thefindings are presented. The final-action a and presents the main themes emerging from the findings.

\section{Litrature Review}

According to Stam (2009), IC is th dift nce bet een intellectual assets andintellectual liabilities. Such liabilities are often overle or by oroanizanons and can even lead to bankruptcy if they remain unrecognized. Conse the the main source of competitive disadvantage value de aration. Subsequently, each category of IC risk is briefly discussed to outline its $r$ sst impact on ompanies.

2.1 Human capital $\mathrm{Sh}_{\mathrm{h}}$. Acc ing to Kupi et al.(2008), particularly the risks related to human capital should be aken into consic ation. For example, staff turnover or long-term absence of key employees can to s rificant implications regarding a firm's productivity (Durst and Wilhelm, 2011). Especially large o mpanies like MNCs some people might consider their job as a springboa to fu. car.ers and only intend working there for a few years. Such employees constar ly se ch for $w$ career opportunities - especially if they come across unfavourable workin. on 2001, has all employees worked for four years or less for the same organization (Macaulay, 2003). On th 1 er hand, in big organizations employees might be less willing to share knowledge due to the "sa ety mentality" and competition between organizational units or individuals. In firms with numerous staff there might be less trust towards others and therefore also less collaboration. Hence, firms are pressured to permanently develop certain expertise once more, which in turn means that they lose critical time compared to their competitors. In a knowledge driven environment, firms cannot afford to lose key employees and their expertise particularly against the background that the battle for talents in certain industries will become tougher (Dess and Shaw, 2001). Moreover, it becomes problematic if outgoing knowledge is used against them (Stovel and Bontis, 2002). Firms need to take measures to reduce voluntary turnover and enhance employee retention (Hislop, 2005). However, as the retention of organization members is not possible forever, the firm's management should plan for staff replacement in due time (Durst and Wilhelm, 2011b). 
2.2 Structural capital risks. According to Stam (2009), "structural liabilities" are destructive forces emerging from structural capital. Such risks are caused if organizational structures or processes are inappropriate or too complicated ). Top management homogeneity, weak planning processes, poor knowledge infrastructure, organizational inertia, complex structure, or a knowledge unfriendly culture belong to this category. Common work practices and organizational routines have often become a pleasant ritual in the firm but do no longer suit the organization's needs and have turned to obsolete inefficiencies. Structural capital is very much interrelated with human capital (Carsonet al., 2004). Structural capital risks might be caused if the components of IC are poorly understood and managed (Zhou and Fink, 2003). Furthermore, some structural capital risks might be related to poor workplace organization or an insufficient information infrastructure.

This also includes the poor documentation of relevant knowledge, resulting in a higher time in projects for example (Singh and Soltani, 2010).

2.3 Relational capital risks. Human capital risks and relational capital risks are hly intert hed too. Turnover of employees can cause turnover of customers (Kupi IC ris ${ }^{\text {th }}$ an b rotat onet al.2008). If contact persons change often, suppliers feel unsure about their usiness an yal y can decrease. Destructive forces concerning external relationships can or nate poor ality of offerings (Harvey and Lusch, 1999) or high relational complexity ( $\mathrm{S}$, " o). Exte yal partners apart from the customer must not be neglected - such as g ner orga tion, universities, consultants, suppliers subcontractors, etc. Company image is a ty interw on with other IC risks and can soon be negatively influenced. Managing reputan me managing the risks related to stakeholder relationships (Murray, 2003). Other essen ar rational o might originate from strategic alliances (Kupiet al., 2008). Opportuni ic behaviour between alliance partners is particularly problematic (Kaleet al., 2000). Conflicts $n$ v lead to th/ situation that mutual learning is inhibited and, hence, the IC endowment of the disadv ged orga nization is negatively affected.

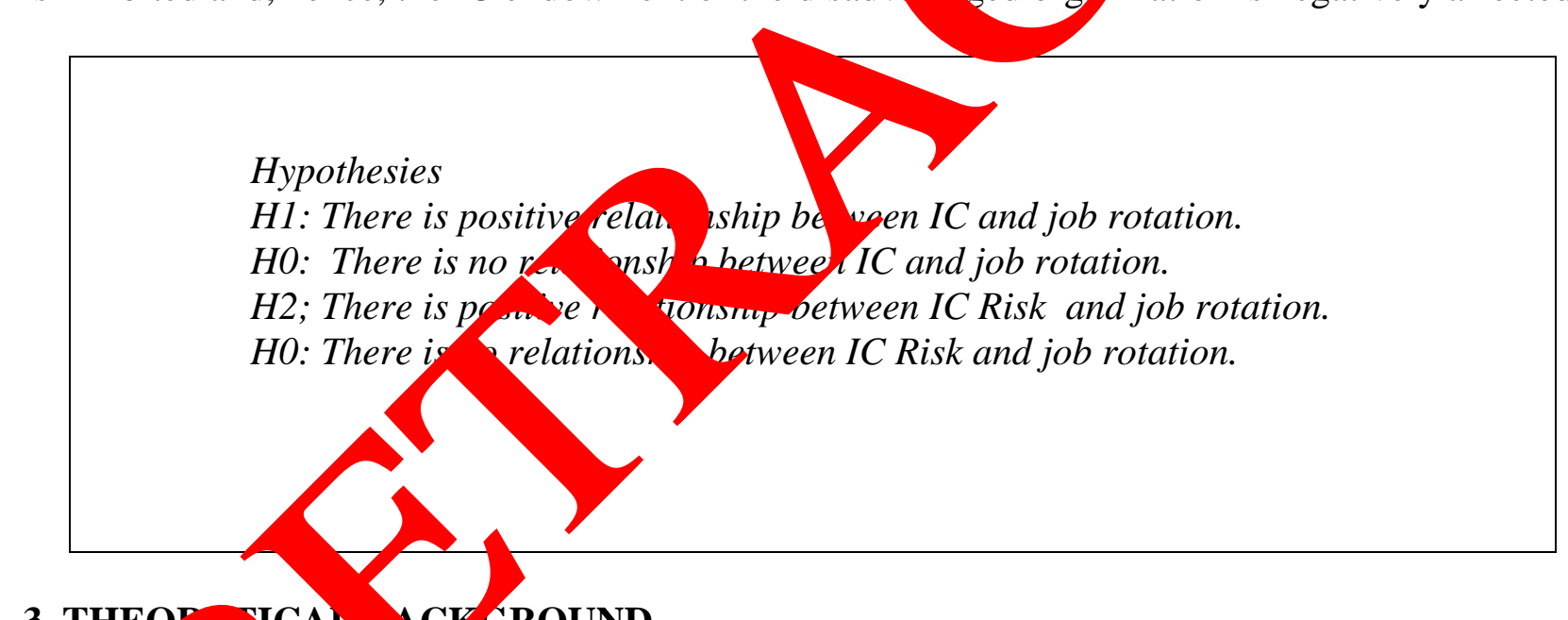

3. THEO ICAL CYGROUND

3.1 Int lectu capita

and "information technology" have triggered dramatic changes in the structure ompanres. These changes in combination with increased customer demands challenge the compan shift their perspective from tangible to intangible resources. Given the new business envizonment and the apparent situation that knowledge has become the most important production factor, a systematic approach to IC is now viewed crucial to remaining competitive Even though more and more organizations and scholars identify the prospects of taking into account IC a great problem still exists: the common language among practitioners and scholars is still missing. Consequently, different definitions are in place (e.g. Edvinsson IC risks and job rotation.

In this study, IC is(based on Andriessen (2004) and Lev (2001)) defined as the core non-monetary resources (lacking physical substance) that are able to contribute to future benefits in organizations. According to many authors, IC can be classified into a number of distinct types of non-physical assets. These classification schemes aim to give a better understanding of what IC consists of. Recently, it appears that the classification of these resources into human capital, structural capital 
and relational capital is increasingly used as a standard perspective (Edvinsson and Kivikas, 2007). This study aligns with it.

\subsection{Risk and its management}

"Risks are usually defined by the adverse impact on profitability of several distinct sources of uncertainty" puts it, risk is "the volatility or standard deviation (the square root of the variance) of net cash flows of the firm". Originally, the term refers to positive and negative outcomes, although in everyday language it appears that risk is mainly associated with danger (Lupton, 2010). Risk management is primarily aimed at identifying, assessing, controlling and Monitering firm risks (Bessis, 2008). Thereby firms should focus on all types of ricl-and their management, yet it seems that firms prefer to focus on financial risks andtb as qua tive approaches because of greater experience (Louisot, 2004). This signifies that the 'ohts into ms' risk profiles are currently unbalanced. Hence, this stresses the need for increand re rech as a lelp to better trace the factors that have an influence on firms' value creation and - deteriora

\subsection{Intellectual capital risks}

In 1999, Harvey and Lusch highlighted the importance of $j$ luo the lial lity side of intangibles to "balance the intellectual capital books" (The authe s assert $\mathrm{t}$ all / t turning into something positive or valuable for a firm is an illusion. $H$ an and Lus assign potential intangible liabilities to process issues, human issues, informan nal is and configuration issues. Harvey and Lusch's work was picked up by Caddy (20 ou tho tried prove the existence of intangible liabilities. By analyzing events at that time uch as the Micrssoft Corporation and the anti-trust case, Caddy found that intangible liabilities re indeed g ven. However, firms have the ability to avoid emergence of intellectual liabilities by if ducing c rtain actions.

Abeysekera (2009), addressing this topic in hi-review of research, noted that the missing consideration of intangible liabilities is lea the consequence that firm disclosure is incomplete. Kupiet al.(2008) conducted exper in crv s in seven Finish manufacturing and service companies to gather data about the risk $m$ ragement of intangible assets in these firms. The authors based their study on three diffo ht types of intangibles-related risk: human capital risk, structural capital risk and relati cap al risk. heir study showed that risks related to human capital viewed as most im an, o. ummuted turnover, losing key personnel, failure in recruitments, etc. Addition $\mathrm{v}$, the aut found that although the firms involved had established different measures to do th these risk, such as job circulation as part of competence transfer, these measures are un not rded as risk management practices. JIC

\subsection{MNCs and jo' rotation}

MNCs, y hare rmally of considerable size, often suffer from increasing bureaucracy and standardized proc that d rease freedom and flexibility. Increasing administration effort leads to numer hierar al cvels with many specialists. Particularly, the costs and efforts for commy icatic and col ol are high (Gooderham and Nordhaug, 2003). Coordination, moreover, is more o le can easily track of what other departments are working on. This might lead to the problem that work is do wice, meaning an inefficient loss of time and money. Additionally, higher competition anong employees on numerous hierarchical levels might lead to the abuse of knowledge as an instrument of hierarchical power and ambition (Hislop, 2005). As a result, this "asset" is not revealed to others but rather kept for securing one's position. Given these general conditions the systematic management and exploitation of the IC stock is inevitable especially for MNCs. This means that knowledge creation as well as knowledge exploitation should represent continuous activities. One of the common tools applied by MNCs to cope with many of these challenges is job rotation. "Job rotation can be defined as lateral transfer of employees among a number of different positions and tasks within jobs, where each requires different skills and responsibilities" (Beattyet al., 1987, quoted in Huang, 1999). According to Eriksson and Ortega (2006), there are three motives for the adoption of job rotation in an enterprise: employee learning, 
employer learning and employee motivation. The first motive addresses an employee becoming more knowledgeable and versatile through the exposure of a greater variety of experiences. Therefore, job rotation might be used as a preparation for top management positions, allowing employees to get a deeper understanding of the business and to develop their abilities. The employer learning theory argues that employers learn about their rotating employees, while observing their performance. Learning about an employee's strengths helps employers to improve promotion decisions, especially in big enterprises. Finally, the employee motivation theory adopts the viewpoint that job rotation enriches an employee's career and reduces boredom, leading to increased motivation of rotating employees. In their survey of Danish firms Eriksson and Ortega found empirical evidence for the employee learning and the employer learning arguments. As shown by Campionet al. (1994), job rotation helps to enrich the career as it inmases job involvement, satisfaction and commitment. Similarly Huang revealed that job rotat on enha s an employee's job satisfaction because employees take over new responsibilities fro time to tin. In particular, different skills for several tasks increase the meaningfulness of wo and le; to enhanced motivation. Going in line with these arguments, Mohr and 7,ghi (2008, ostr ate a positive relationship between an employee's job satisfaction and a higb volve nnt wo design. Such work designs require a high degree of problem-solving, inter-gr p eration ha learning. Among others, these high involvement work designs dispose $g^{f}$ job rota Ad ationally, job rotation serves as a tool to build organizational collective know c $\mathrm{a}_{\mathrm{a}}$ As emplo, s rotate between departments, they transfer collected experiences to each a $r$ an veate knowledge networks throughout the entire organization. This implies that kn wvicuge does onger depend on some experts but is disseminated within the entire entity. Ho g and Vai (2008) name job rotation as one of the central knowledge-sharing mechanisms in cr -functional/virtual teams. Moreover, job rotation can be helpful for MNCs with heterogeneo taff to ecrease distances and barriers between employees from multicultural back-rounds. Whe job rotation process can be viewed as advantageous for IC management, it rails risks. The change from the predecessor to the successor is a critical stage. If no kno vle go socumented by the predecessor the "newcomer" needs to fight his or her way to nece sary knowledge to fulfil tasks satisfactorily. This can be a very time-consuming proce which might also decrease motivation among the "newcomer" and corresponding vor ars. In the worst case, this leads to a "broken learning cycle", meaning that the whe -ren nteu me organization and mistakes happen repeatedly). If organizations are not awar f this prov they risk losing precious time and inhibit learning from previous experiences. $N$ ore ortantly s, ch an unsystematic handling of knowledge can be risky: knowledge gets lost $d^{\text {n }}$ ing the $\mathrm{J}$ rotation process.

\section{RESEARCF TETH DOLOGY}

Taking the s aim in exploratory (qualitative) research approach was regarded as more appropria The so ion of a qualitative approach allows the researchers to get close to partici ants a their th king in order to scrutinise the entire research problem Morehouse, Thus, the foc tar standing people's words and behaviour. To do so the researchers became an integral $\mathrm{p}$ of the investigation. The company selected for this study provides products and services to fuction professionals. The focus on a single firm was justified because it was viewed as a typical MNC given that it operates in different markets and has locations in more than 120 countries worldwide (Yin, 2003). In this firm job rotation is used as a personnel development tool to develop "business partners" in the company - highly qualified professionals who acquire knowledge in different management fields. This job rotation process comprises a change of workplace for "business partners" on a regular basis. This process is intended to encourage the development of cross-functional expertise as well as the formation of internal knowledge networks. Access to the company was established due to a work relationship of one of the authors. IC risks and job rotation Managers working in departments affected by the job rotation process as well as employees having made experiences with job rotation represented the level of analysis. This allowed the researchers to obtain insights from different perspectives helping them to reduce any 
biases given, rather than relying just on one group of individuals The sampling strategy applied for the informants was what Patton (2002) referred to as criterion sampling. This strategy of purposive sampling comprises the selection of cases that meet some predefined criteria. The criteria for the managers were the possession of long-year experience within the $\mathrm{MNC}$ and the belonging to the upper levels in firm's hierarchy. On the other hand, employees were selected who have at least once participated in the job rotation process. After having selected a "pool" of possible candidates with the help from the side of the MNC, these individuals were contacted and asked for their willingness to participate in the study. In total, six top managers were involved, belonging to various departments of the MNC.

Data were collected through semi-structured interviews with mentioned eleven participants. This technique is regarded as appropriate when very little is known about the subject in han-thus it is suitable when the topic.

Finally, the interview questions for managers ended with questions regarding ris 1 vareness o ing job rotation and experiences with such. Similarly, the interview guide foremp res incl ded questions related to the job-rotation experience. During this procedure atte ion was p to nsure that an appropriate language was chosen. Thus, the use of theoretical incept ynkno by the participants should be avoided .For example, in the case of the term "ten capi the terms "soft facts" and "knowledge" were applied and examples were us d to gath ata oout the three IC risk dimensions.

The interviews took place between August and September 2a Due reographic dispersion, four interviews were conducted by phone (three managers an - om employ Most of the interviews took about 45 minutes to one hour of time. In the major $y$ of cases, the in erviews were recorded in consent with the interviewees to facilitate data collec $n$ as well a analysis. Besides, field notes were taken by the researchers during most interviews to ture rele ant points.

Afterwards, interview summaries were proc waed whic the most important aspects discovered. Second, data display is conducted aizing the data into charts, diagrams or other visual forms. This was done when analysing the ind no the research questions, namely the managerial awareness of IC risk du-ing job $r$ ation and the managerial perception of IC risks. The most important data from ea $\mathrm{m}$. tger wa displayed in an Excel-matrix under different categories (e.g. IC risks during ro tion. hunan capital risks, relational capital risks, and structural capital risks). After of manasus' data were displayed under these categories, and overview over the most re ant collec. data were present. This helped to compare the data, find similarities or differenc a an conc asions. The third research question, which deals with IC risks during job rotat $n$, was $a_{\text {. }}$ ered by summarizing the depictions from the five respondents. The relevant data were summed under different categories (e.g. time to retrieve knowledge, duration of han ver et and afterwards a report about this part of interest was produced.

\section{FINDI}

5.1 IC isks à experie d during job rotation

Four of of experiences with job rotation had to regenerato "ot of knowledge on their own during the change from one job to the other:

The followin $\chi$ summarizes the IC risks related to the job rotation process as

$>$ experisnced by the interviewees.:

$>$ High levels of stress among participants.

$>$.Frustration and demotivation.

$>$.Inefficient workflows - "reinventing the wheel".

$>$ Loss of productivity, time and money.

$>$ Loss of knowledge and expertise (leading to repeated mistakes, wrong decisions, high costs etc.).

$>$ Inhibits progression of corporate knowledge base.

$>$ Decreased workplace attractiveness!damage to corporate reputatio 


\section{CONCLUSION}

The purpose of this study was to shed light on the perception of IC risks by managers. Prior research has tended to underestimate this aspect. It is important to understand how managers deal with possible risks related to IC, as this asset is significant for a firm's competitive advantage and survivability. The particular interest was to investigate the perception of IC risks in the job rotation process often applied in MNCs. Besides, this research has focused on the relationship between IC risks and the job rotation process. In prior research, job rotation has mainly been associated with its impact on productivity The findings imply that the managers involved are only aware of a limited number of IC related risks, e.g. staff turnover or undocumented knowledge. Other possible IC risks are not taken into account or are not appreciated. This seems to be valid for risks related to the job rotation process too. This apparent neglect might be a consequence of the time pres agers are facing. This consideration raises the question of how to implementIC knowledg risk management approaches. Under time pressure, it is comprehensible that cia day bus ess receives priority and that knowledge matters (e.g. documenting knowledge ane har taker into account. If transition times are very short sufficient knowledge transfers are volly Knowledge risks, moreover, can sometimes not be prevented or predicteon the prol en s occur if people come together. For

example if the relationship between predecessor and successor is sed on an they will not be likely to share a lot of knowledge with each other - regard'ss o corporate culture promoting knowledge sharing. Similarly, if someone is unexpectedly ont man ars need to react fast and probably did not take proactive measures because they did not anticipa this situation. Thus the time needed for these measures must be weighted up th the knowledge risks and particular their implications for the firm.

Although situations as the ones outlined previously wh lways ccur, it is an important task of management to keep these risks to a minimui Came of trumonstrated problems in this study could be solved by granting more importance i Kiny doe as a fundamental resource of a firm's competitiveness. This would justify that the man $\mathrm{g}$ is in ne case firm are conceded more time for the succession process related to the otation rocess and other situations involving knowledge issues. As a result, they could tak more me for nsiderations regarding the range of IC related risks and suitable measures to tok

These measures could com ensate concluded that a sensitiz a manas for the variety of IC related risks and their probable implications constitute the in amental starting point towards solution. A highly recommended beginning would b an exchang atween the managers and those organization members having already experien ed the pros and ontras of job rotation to broaden the perspective of the former. This would ken naragers o better understand where possible risks might be located. Thus managers need to ady to isten to those in the company directly concerned by job rotation. In order fo 10 ks to ie ve acceptance and appreciation in the managers' mindsets, the Human Resor s de artment gould play an educative role by designing guidelines, checklists or ways of moniton antation of job rotation with regard to the handling.

This study ntributes to the development and extent of the IC risks overview discussed by thereby bring $s$ in new aspects that are important with regard to the job rotation process The new items derived from this study are presented in Italics. This extended list helps to obtain a more complete and specific understanding of the varieties and characteristics of IC related risks firms could face in today's business environment. A better understanding of IC risks is viewed as a fundamental

contribution to the IC literature as it makes it possible to have a more complete and balanced picture of the concept of IC.

Firms respectively managers using job rotation must be aware of the risks associated with IC and have in place ways to handle unwanted outcomes. The list of IC risks possible in the job rotation process may ensure that the individuals in charge are informed and can better anticipate and respond to critical events. 
This research has some limitations. First, the results were gained from a single organization thus statistical generalisation is not possible. However taking the exploratory nature of the study, one might be able to make an analytical generalisation Another limitation is related to the fact that only executive personnel were included in the interviews meaning that only a limited view of the "manager" was provided. Future research could also include other perspectives, e.g. that of the firm's risk manager, to obtain a more balanced understanding of the IC risk perception. To check for the findings' transferability future research should be conducted in other organizations, e.g. similar MNCs. It is possible that individuals working in other types of organizations might place emphasis on different IC risks. These limitations may already present the basis for future research. Additionally given the time constraints managers are facing nowadays, future research may focus on the weighting of the IC risks identified. This enhances knowledge in that area and aces the danger of overlooking significant risks due to lack of time

\section{Refrences}

[1] Neef, D. (2005), "Managing corporate risk through better knoy edge manag "The LearningOrganization, Vol. 12 No. 2, pp. 112-24.

[2] Ortega, J. (2001), “Job rotation as a learning mechanism”,M ragemen ience, Vol. 47 No. 10, pp. 1361-70.

[3] Patton, M.Q. (2002), Qualitative Research \& Evaluati Metho 3rd ed., Sage, Thousand Oaks,

[4] Saunders, M., Lewis, P. and Thornhill, A. (2007), search Methods for Business Students, 4th ed.,Pearson Education Limited, Harlow.

[5] Singh, A. and Soltani, E. (2010), "Knor Modge manow practices in Indian information technology companies",Total Quality Man Ko. Vol. 21 No. 2, pp. 145-57.

[6] Stam, C.D. (2009), "Intellectual liabilities: asons rom the decline and fall of the Roman Empire", The Journal of Inform? nd Kno ledge Management Systems, Vol. 39 No. 1, pp. 92-104.

[7] Stewart, T.A. (1999), Int tua apitar. ne New Wealth Of Organizations, Doubleday, New York, NY.

[8] Sullivan, P.H. (19S "P ing from intellectual capital",Journal of Knowledge Management, Vol. 3 No. 2, pr $182-42$.

[9] Sveiby, K (1997 The New Organisational Wealth: Managing \& Measuring Knowledgebased Assets, ett-Ko ler, San Francisco, CA.

[10]Wii, (199) "Kowledge management: an introduction and perspective",The Journal of $\mathrm{K}$ wled a Manag ment, Vol. 1 No. 1, pp. 6-14

( Received 30 May 2015; accepted 02 June 2015 ) 